\title{
Note on Transliteration
}

ALL WORDS from the Sanskrit, Hindi, Urdu, and Marathi that occur more than once or twice in the text are transliterated with diacritical marks on their first appearance; thereafter, they are printed without diacritics and their spelling is adjusted to the commonest usage: $c h$ for $c, v$ or $w$ for $v, s h$ for ś and ș. Some specific adjustments have been made for the Marathi language: $r u$ for $r$, and $d n y a$ for gya; in addition, many words ending with a consonant are not pronounced with the usual devanaggari short vowel $a$, which has therefore been omitted. Because plural forms may be unfamiliar, I have added an $s$ to create the plural of transliterated words. The titles of songs, chants, poems and prayers, and entire sentences have not been transliterated. Terms and names that occur more than once or twice in the text are listed in the Glossary.

The Marathi-speaking region of the Bombay presidency became Bombay state after Indian independence; the state was renamed Maharashtra in 1960. The name of its capital city was changed from Bombay to Mumbai in 1995. Throughout this book, I use the modern names for the state and city, except where the historical context requires "Bombay." 

Schooling Passions 
